\title{
ReFlections FROM TeACHING ASSistants in CoMbined LeARning Assistant ANd Course Grader Roles
}

\author{
Natasha Lanziner, Hannah Smith, and David Waller \\ Queen's University at Kingston, Ontario \\ natasha.lanziner@queensu.ca, hannah.smith@queensu.ca, and david.waller@queensu.ca
}

\begin{abstract}
Integrating the roles of learning assistants and course graders into a single teaching assistant position can be beneficial both to students and to teaching assistants. A critical reflection of teaching assistant experience in undergraduate design courses was undertaken. Benefits to students include meaningful, individualized guidance in assessment, the communication of expectations and concepts from a unique perspective, and increased approachability.

The teaching assistants also benefit from practical experience in teaching and mentoring, gaining skills in leadership and communications. However, integrating learning assistant and course grader roles creates a more challenging position, requiring deep understanding of course content and communication strategies to be successful. This insight may be used to improve or develop design courses using the combined model and to help prepare teaching assistants for this demanding but rewarding role.
\end{abstract}

Keywords: Graduate teaching assistants; learning assistant model; course graders; engineering design courses

\section{INTRODUCTION}

Engineering design courses are often taught using the problem-based learning pedagogy in active learning environments. In such environments, teaching assistants are often required to adopt roles that differ from those in traditional, technical engineering courses. The roles of graduate teaching assistants can be classified into three categories: (a) instructional roles; (b) grading roles; and (c) learning assistant roles. This paper addresses a combined model of roles where the grading roles and learning assistant roles are integrated.

The learning assistant (LA) program, developed at the University of Colorado in 2003, uses undergraduate LAs to facilitate active engagement in large-enrollment STEM courses. LAs are used in course that have undergone course transformation to incorporate best practices in teaching, which often incorporate the problem-based learning pedagogy and active learning environments. Thus, the program is applicable to the majority of engineering design courses. For the LAs, the program offers experiential learning experiences in teaching as well as training in pedagogy. The LA program also serves to find and recruit talented undergraduate students that may wish to become teachers [2]. In comparison to the LA program, course graders are often removed from the classroom setting. In many engineering courses, graduate students are assigned teaching assistant positions with course grader roles as part of a funding package. In such cases, the graduate students' experiences and learning opportunities are limited.

In the combined model, teaching assistants act as LAs for groups of students while also acting as graders for the same students. Generally, research on the role of teaching assistants on students' learning in engineering design courses is limited [4], [5]. Thus, this paper serves to add to the literature by detailing and reflecting on the experiences of three graduate teaching assistants in the combined model [7].

\section{THE ENGINEERING DESIGN AND PRACTICE SEQUENCE}

Since 2011, the Engineering Design and Practice Sequence (EDPS) is a core requirement for all engineering students. The EDPS spans all four years of every engineering program at Queen's University. In each of the first two years of the EDPS, students take faculty-wide courses, EDPS I and EDPS II. In the third and fourth year of the program, students take program-specific courses and can elect to take the optional courses in the Multidisciplinary Design Stream (MDS), APSC381 and APSC480, in third and fourth year, respectively [1]. The experiences and reflections detailed in this paper were obtained and developed from teaching assistant roles in EDPS I, APSC 381, and APSC 480.

In these courses, students complete design projects while working in teams of three or four. In EDPS II, there are two major design projects. The first project (PI) is open-ended and multidisciplinary in nature, while the second project is discipline related and often includes a prototyping or design-of-experiment requirement [1]. Course instruction is provided in biweekly lectures and 
active learning workshops. Teaching assistants act as LAs in the biweekly workshops. In APSC 381, students complete a term-long project while working in multidisciplinary teams. The projects are designed specifically to aid in students' learning of the engineering design process. In APSC 480, students work in multidisciplinary teams to complete an industry-sponsored project that is two-terms in duration. Instruction and active learning is incorporated into weekly lectures in both APSC 381 and APSC 480 [3]. Teaching assistants are present in some lectures and also conduct one-on-one meetings with their assigned teams. In each course, the assessment of engineering design, professional practice, and communication is conducted by assessing scaffold, consecutive engineering design reports [6]. Teaching assistants act as course graders when grading such reports. In the process of design report grading, grades are assigned using rubrics and written, formative feedback is provided [6].

\section{THE COMBINED MODEL IN PRACTICE}

In practice, the successful implementation of the combined model depends heavily on the characteristics of the teaching assistants and students. Successful implementation of the model is considered to result in measureable improvements in the facilitation of students' learning when compared the grader only model.

\subsection{Teaching Assistants}

The authors of this paper have a combined eight years of teaching assistant experience in 2nd, 3rd and 4th year design courses. We are current Master's students completing research in engineering education topics, and have recently graduated from accredited engineering programs in Ontario. From a student perspective, we are relatively well versed in design process and techniques, and pedagogy. However, like undergraduate students, we are very much in the early stages of our learning. Of the three authors, two completed EDPS II, APSC 381, and APSC 480 as undergraduate students and bring personal experience to our roles as teaching assistants.

3.1.1 Training. Training of teaching assistants is partly achieved by a peer training model, whereby more experienced teaching assistants guide those who are new to the role. In the peer training model, guidance is provided on feedback strategies. The more experienced teaching assistants have previously received guidance from course instructors. Additional training is provided from course instructors on course content and student-interaction strategies through regular meetings. Online resources are also utilized for grading and feedback training. Often, the students selected as teaching assistants have performed very well in the courses, and are thus quite familiar with course content and structure. These students are also selected based on their strong communication and professional skills.

\subsection{Engineering Design Students}

The incorporation of the LA program into the combined model creates opportunities for individualized instruction. An understanding of the differences among students is necessary for individualized instruction to be successful. For the implementation of the combined modeled, the two important areas in which engineering design students differ are their value of engineering design and their maturity and professionalism.

3.2.1 Value of Engineering Design Elements. EDPS II and the courses in the MDS include instruction on professional engineering elements and engineering design tools for creative thinking and decision making [1], [3]. From our experiences, students do not necessarily value the various engineering design elements. For the purpose of facilitating students' learning, we consider students to have three different levels of value: (a) high value; (b) indifference; and (c) no value. Students with high value for engineering design elements are typically observed in the option MDS courses, whereas students with no value are most often observed in the mandatory EDPS II course. Indifferent students are most commonly observed in the second and third year courses, EDPS II and APSC 381, respectively.

3.2.2 Maturity and Professionalism. From the three observed courses, students' maturity and professionalism seem to increase as they progress through years of study. However, it is possible that this improvement is due to the optional nature of the MDS courses. Nonetheless, students' maturity and professionalism are important factors when determining the best approach for engaging students. We consider students' maturity to be manifested in their willingness to learn, despite their value of the course content whereas students' professionalism is manifested in their interaction with TAs as well as their attitudes towards feedback. For purpose of engaging students, we classify students as having either high or levels of maturity and professionalism. The majority of students in the MDS courses are in the high level whereas many students in EDPS II are in the low level. As students in these courses work in teams to complete projects, the maturity and professionalism of a student within one team seems to impact the engagement and learning of other students in the team.

3.2.3 Implications for Facilitating Learning. In the combined model, students' learning is primarily facilitated by teaching assistants in classroom activities and meetings, and through written, formative feedback on the design 
reports. We have observed that the best approaches for facilitating students' learning in these areas differ according to students' value of engineering design elements and their maturity and professionalism. Students with a high value for the engineering design elements are often the easiest to engage, whereas students with no value for engineering design elements are often the most difficult to engage. Mature and professional students are not necessarily the easiest to engage, but they are typically responsive and respectful towards teaching assistants, which can make the task of engagement easier. Students with low levels of maturity and professionalism can be easy to engage, but in some cases they are friendly to the point of impropriety. Generally, the easiest students to engage have high levels of maturity and professionalism, and value of the engineering design. These students are often the most advanced, so they require teaching assistants to have mastered the course content.

\subsection{Formative Feedback}

In EDPS II and the MDS courses, students receive formative feedback from teaching assistants in writing on design reports as well as in-person during classroom activities and meetings. The primary purpose of the formative feedback is scaffolding. Formative feedback can be categorized as general summary feedback or task-level feedback [8]. Both categories of formative feedback are used in the courses in the form of written feedback and the use of the rubrics outlined in [6]. In our experience, the combination of the grader and LA roles allows for higher quality task-level feedback. Improvements to the quality of general summary feedback as a result of the combined model is limited. In a review of literature on task-level formative feedback, Shute suggested that for most students, feedback with higher levels of specificity but lower complexity resulted in improved learning. However, characteristics of the learner are of importance to the impact feedback [6]. Our experiences also suggest that the characteristics of the learner or student are of importance.

For the purpose of this paper, we have used Shute's simplification of feedback complexity to convey the best observed feedback methods for different engineering design students. Formative feedback can be classified as either simple or elaborated. Simple feedback is provided in the following forms: (a) no feedback; (b) verification of correctness; (c) repeat-until correct feedback; and (d) error flagging. Elaborated feedback provided in the following forms: (a) topic contingent; (b) response contingent; (c) prompts; (d) misconceptions; and (e) informative tutoring [6]. Depending on the feedback context and our past experiences with and knowledge of specific students, different forms of feedback may be best. It is because of this dependency that the combined model is advantageous.
3.3.1 Engineering Design Report Feedback. In the context of written feedback on engineering design reports, simple feedback often lacks specificity, and thus is less beneficial to students. Simple feedback only seems to be effective for students that convey mastery of the learning outcomes. Within the category of elaborated feedback, we have found that for written reports, different forms are more applicable to different students. Students with high value for the engineering design elements often benefit from feedback in the form of prompts and informative tutoring. These forms help to guide students in how to proceed without providing the correct approach [6]. Students indifferent to the engineering design elements seem to benefit most from the topic and response contingent forms. Together, these forms address the course topics and the specific application of the topics by the students. In some instances, the topic contingent form involves re-teaching of the course content [6]. We have found that most of our feedback to students that seem to not value the engineering design elements is in the topic and response contingent, and misconception forms. Typically, these students do not convey an understanding of the course topics and will often ignore or misapply the topics. Although prompt feedback is applicable to these students, in instances where we have provided it, it is usually ignored. Maturity and professionalism plays a smaller role in the determination of the best type of feedback, though students with high levels are usually responsive to all forms of elaborated feedback. In some cases, we have observed students with low levels become confused when a variety of feedback forms are used on a single engineering design report. In-person interactions with students are important when attempting to estimate how students value the engineering design elements. Without the opportunity for interaction, as in a grader only role, we would have more difficulty in selecting the most appropriate form of feedback.

3.3.2 In-Person Feedback. In most cases, the best forms of feedback provided in-person correlates with the best written form when considering students' value of the engineering design elements. However, when providing feedback in-person, there is an opportunity to engage students that seem not to value the engineering design elements. In our experience, students that do not value these elements seem to disregard the utility value of the elements. As teaching assistants, our professional experience is limited, but we can provide short-term examples of utility value. This often relates to examples of application in future courses or in gaining summer employment or employment after graduation. When compared to the engineering design report feedback, the impact of in-person feedback on students' learning is highly dependent on students' maturity and professionalism. During class activities and meetings students need to balance interactions and intellectual 
considerations with a more people within a shorter time frame. Thus, we have found it is best to minimize the number of topics on which feedback is provided to ensure information is retained. Despite the added complexities in the in-person context, we have found that elaborated feedback is still more effective than simple feedback. Prompts are the often most applicable and effective form of feedback. Because of the grader role, we have a greater awareness of each team's project and work, and thus can provide specific feedback efficiently in-person.

3.3.3 Acceptance and Incorporation of Feedback. Students' acceptance of feedback seems to be highly dependent on their level of value for engineering design elements and their maturity and professionalism, no matter the form of feedback provided. Generally, students that value the engineering design elements accept and incorporate feedback well. Students that do not value such elements will often ignore feedback, and, in some cases, will contest the knowledge and abilities of the teaching assistants. Students that exhibit high levels of maturity and professionalism seem to consistently accept and incorporate feedback well.

\section{PERCEIEVED BENEFITS TO STUDENTS}

The creation of useful and effective formative feedback is dependent on the integration of the grader and LA roles. The LA role allows for greater amounts of interaction with students, which results in clear advantages to student learning. Student teams are assigned to a single teaching assistant for the duration of the course, which reduces the student to teaching assistant ratio. With a reduction in ratio, communication with students becomes easier, as teaching assistants are more readily available to provide guidance to students. Other notable benefits of the combined model are immediately evident: students seem to be more comfortable communicating with their peers and teaching assistants, and have fewer concerns asking for help.

\subsection{Asking for Help}

Particularly in the second year course, EDPS II, students seem to be willing to communicate confusion and frustration with concepts or processes. Many of our interactions with students began with: "I'm sorry if this is a stupid question, but...". This frustration and self-doubt seems to be easier to express to someone they view as a peer - someone who has experienced the courses in question first hand, and who they perceive as being more intimately aware of the challenges of the undergraduate experience. From our experience as students and teaching assistants, asking for help is an important part of the learning process. This is particularly in engineering design courses where problems are open-ended and with no single correct answer.

We have found that our relative proximity to the learning process can be beneficial to students in how we approach providing feedback and examples. As two of the three completed the courses as undergraduate students, we often refer to our own experiences and struggles as students in the courses. At times, this results in analogies and explanations that differ from those of the more advanced instructors.

\subsection{Collaborative Guidance and Engagement}

Because of the reduced difference in experiences, there is an inherent informality in the combined model. Often, this friendly relationship produces the best results in students. They are relaxed and more willing to engage. We have often had meetings with students where they are jovial and friendly, quick witted and creative. In this way, we (as teaching assistants) are able to actively collaborate with students on their ideas and processes, giving input where necessary and challenging assumptions and biases in a safe environment. The open atmosphere is key to collaborative and creative problem solving. If a teaching assistant can be present in such an environment, it allows input and questions while engaging in active thinking and problem solving, and guiding without hindering the student experience. But, depending on the student, the approachable but professional relationship can be interpreted.

\subsection{Understanding Professional Interactions}

Given the nature of the teaching assistant role, professionalism is key in all interactions with students. A friendly relationship must be maintained to reap the full benefits of the learning assistant model; however, this relationship runs the risk of encouraging unprofessional interaction.

This is generally more evident with students in second and third year courses. Some of these students are friendly to the point of impropriety - attempting to connect with teaching assistants over social media or inviting them to team outings and events. It is the responsibility of the teaching assistant to conduct themselves professionally in these circumstances, making the boundaries of professionalism clear. This is a tricky line to toe - the gap between an instructor and a student seems to be a clearer boundary. Particularly in courses designed to teach students professional skills and competencies, these interactions blur the line between educator and friend.

The shared experience also can be misconstrued as permission to commiserate with the teaching assistants; generally to complain about or discuss course content, workload or demanding deliverables. Again, this is evident generally in lower level courses with younger students. In 
fact, this "buddy" mentality can, once again, devolve into unprofessional interaction. On several occasions, we have had students directly asked to be marked more generously. This is a request that, we suspect, would never be made of an instructor for the course, or of a teaching assistant who was solely responsible for grading and had no personal interaction with the students. Again, we encounter a difficult situation: what is the appropriate level of friendly, personal interaction to encourage easy communication, but discourage informality?

This is an excellent opportunity for students to engage in professional skills development. A professional relationship is expected in all relationships in the design courses in question: student to student, student to teaching assistant, and student to instructor. By expecting professional communication and interaction with teaching assistants (who are generally close in age to the students), we give students a proverbial 'stepping stone' to develop proper communication and behavior in a professional context, with a peer. Again, this presents a low risk environment to students, developing their professional skills while interacting with teaching assistants who have shared experiences.

\subsection{Consistency in the Learning Experience}

By grading the engineering design reports, we can provide targeted guidance in classroom activities. Instead of providing general guidance on a topic, teaching assistants can provide guidance in the context of the project on which the students are working. This can drastically increase the value the students place on that guidance, because the application is clearer. The combined model also increases consistency in the guidance and feedback that students receive as it comes from one individual. Consistency is improved both in the content of the feedback as well as the form of the feedback.

\section{PERCEIEVED BENEFITS TO TEACHING ASSISTANTS}

Repeated exposure to course concepts and techniques provide a unique experience for teaching assistants. We are able to develop detailed knowledge of the topics presented, mainly due to repeated exposure with different teams, and guiding the students through problem solving in unique and innovative ways. This improves proficiency in applying course concepts and material in our own engineering practice. The teaching assistants can learn from the students, experiencing novel application of concepts on a regular basis.

\subsection{Practical Experience in Teaching and Mentoring}

The teaching assistants also benefit from practical experiences in teaching and mentoring undergraduate students. Through consistent interaction with students in classroom activities, team and student meetings, electronically, and through written feedback, the teaching assistants are given numerous opportunities to engage with student teams. This variety of interaction provides many platforms for guidance and mentoring, and interaction ranges across clarification of course content, application of design tools and techniques, professional skills and project management, and clear technical communication strategies.

The more personal relationship between teaching assistant and student is a benefit to both parties. From the teaching assistant perspective, it provides a more comfortable environment to develop teaching experience and experiment with new methods. It is rare that a teaching assistant would be working with more than 5 students at any given time, allowing a small-scale introduction to pedagogical techniques and methods. This is a low-risk environment compared to a more traditional lecture or tutorial based teaching assistantship. This format allows teaching assistants to develop confidence in their teaching and mentoring ability with small groups of students through personal interaction.

\subsection{Professional Skills Development}

Through mentoring and communication with student teams, teaching assistants are given an opportunity for professional skills development. Through our experiences in EDPS II, APSC 381, and APSC 480, we have enhanced our leadership, written and oral communication, and conflict resolution skills.

Teaching assistants are often called upon in a project manager capacity. This includes communicating project objectives and tutoring in project and time management skills and strategies, as well as ensuring that teams are on track to successfully complete the projects at hand. Essentially, each teaching assistant is leading 4-5 teams of students in any given course. This is excellent management and leadership experience, which is transferable in a professional capacity.

Communication skills are developed to a great degree through written feedback on deliverables, as well as oral communication with students in a classroom setting. Teaching assistants must be able to give clear and concise explanation of expectations, as well as clearly communicate application of concepts and techniques. This is developed through individual interaction with students and instructors, and extremely beneficial in all future professional interactions.

In any team-based project, sometimes interpersonal conflict is unavoidable. Often, we see student teams who have a difficult time interacting or completing project work due to such conflicts. Teaching assistants are regularly 
called on to provide guidance through these disagreements, leading discussion of team expectations and implementing strategies for clear communication and conflict resolution. On occasion, students come into conflict with teaching assistants, generally because they have received poor marks on submitted reports or assignments. Again, this is an opportunity for development of conflict resolution skills in teaching assistants. Maintaining a calm and understanding demeanor has proven crucial to resolving these events. Interaction with students of all backgrounds, experiences, and personalities is highly valuable. Each student benefits from an individualized style of communication, which often helps to avoid conflict.

\section{IMPLEMENTATION CONSIDERATIONS}

We believe that the perceived benefits to students and teaching assistants from the combined model could be obtained in other engineering design and professional practice. Thus, we would like to offer some considerations for implementation of such a model from the teaching assistant perspective, which may differ from considerations from the perspective of a course instructor.

\subsection{Course Design}

From our experience, the most important elements of the course designs that facilitated our success were the structure and location of the classroom activities, and the design of course assignments. Classes were held in flatlevel rooms with ample space for student teams to collaborate, and more importantly, for teaching assistants to navigate through. We suspect that if held in a lecturestyle room, it may be more difficult for teaching assistants specifically to engage students as we feel that we have less authority than instructors have with students. If implementing this model, we suggest that classroom activities be designed in such a manner that a teaching assistant can easily drop by to assist with learning, but so that they are not necessary for the entire experience. For us, it was easiest to move among teams when worksheets were provided. Ratios of $24: 1$ of student to teaching assistants (6 teams to 1 TA) seem to be the maximum to allow for manageable responsibilities for teaching assistants. However, this could vary with the relative amounts of grader and LA responsibilities.

\subsection{Inform Improvements to Course Design}

Because we interact closely with students in two roles, we may be in a somewhat unique position to offer insight into overall student learning. Such information may be beneficial for instructors when they are making changes to the design of courses. Course graders and LAs can both indicate areas of content that students struggle with.
However, course graders normally have an assessment perspective while LAs have a learning process perspective. In the combined model, teaching assistants have both perspectives, thus they can more easily make connections between the learning process and engineering design reports.

\subsection{Recruitment of Engineering Education Graduate Students}

Although the experiences detailed in this paper were those of graduate teaching assistants, the combined model could be implemented with undergraduate engineering students as a method for recruiting engineering education graduate students. To do this, additional elements of the LA program training model could be implemented, as the LA program serves to recruit undergraduate students for teaching programs [2]. Two of three teaching assistants in this paper, who now conduct engineering education research, initially held teaching assistant positions in the combined model as undergraduate students. Thus, with additional structure it is possible that when implemented in engineering design courses, this model could stimulate graduate student engineering education research in Canada.

\section{CONCLUSION}

From our recent experiences as undergraduate students and as graduate teaching assistants, we recommend the combined grader and learning assistant model for undergraduate engineering design courses. The main benefits of the model include consistent, individualized formative feedback to students, and increased accessibility and approachability of members of the instruction team. These benefits may increase student learning and value of engineering design elements. Although the model could be applied to other engineering courses, we suggest that the problem-based nature of design courses align well with the model.

\section{Acknowledgements}

The authors gratefully acknowledge supportive funding from the NSERC Chair in Design Engineering and from the Faculty of Engineering and Applied Science at Queen's University. We would like to acknowledge and thank David S. Strong, the coordinator of the courses in which we were involved, for providing us with such an excellent opportunity for learning and professional development in the field of engineering education. We would also like to acknowledge and students from whom the insights were developed. 


\section{References}

[1] Brian M. Frank, David S. Strong, and Rick Sellens, "The professional spine: Creation of a four-year engineering design and practice sequence." in Proc. ASEE Annual General Conf., ASEE 2011, (Vancouver, BC; 26-29 June 2011), 2011.

[2] Colorado Learning Assistant Program, Colorado learning assistant program: Overview. Boulder, CO, 2010 From http://cadrek12.org/sites/default/files/04_LA_Program_Over view_101110.pdf

[3] David S. Strong, "An approach for improving design and innovation skills in engineering education: The multidisciplinary design stream," International Journal of Engineering Education, vol. 28, no. 2, pp. 339-348, 2012.

[4] Fen-Yu Tseng, Jeng-Yi Shieh, Tza-Wah Kao, Chau-Chung $\mathrm{Wu}$, Tzong-Shinn Chu, and Yen-Yuan Chen. "Developing and evaluating medical humanities problem-based learning classes facilitated by the teaching assistants majored in the Liberal Arts," Medicine, vol. 95, no. 6, pp. 1-6, 2016.
[5] Kelsey J. Rodgers, Aladar K. Horvath, Hyunyi Jung, Amanda S. Fry, and Heidi Diefes-Dux. "Students' perceptions of and responses to teaching assistant and peer feedback," Interdisciplinary Journal of Problem-Based Learning, vol. 9, no. 2, 2015.

[6] Natasha Lanziner and David S. Strong, "Designing rubrics to assess Engineering Design, Professional Practice, and Communication Over Three Years of Study," in Proc. CEEA Canadian Engineering Education Conf., CEEA 2016, (Halifax, NS; 19-22 June 2016), 2016.

[7] Shmuel Ellis, Bernd Carette, Frederik Anseel, and Filip Lievens, "Systematic reflection: Implications for learning from failures and successes," Current Directions in Psychological Science, vol. 23, no. 1, pp. 67-72, 2014.

[8] Valerie J. Shute, "Focus on formative feedback," Review of Educational Research, vol. 78, no. 1, pp. 153-189, 2008. 